\title{
Transaction Services, Neutrality of Money, and Marginal Impatience
}

\author{
Hiroaki Hayakawa ${ }^{a}$ \\ Universiti Brunei Darussalam
}

\begin{abstract}
This paper examines the issues of neutrality and optimum quantity of money in the context in which transaction services of money are imputed and enter a utility functional of a recursive class. We show that the results are diametrically different from the case of money in the utility function. The reason is due to the fact that in response to changes in nominal interest rates, agents adjust their real balance holdings hyperbolically to keep the marginal rate of substitution between real balances and consumption unitary. As of steady state, we show that capital intensity, consumption, transaction services, the rate of time preference, and agent's welfare are all invariant to monetary expansion, which is termed hyperneutrality. This strong neutrality holds whether the marginal impatience is increasing or decreasing in consumption and real balances. Friedman's argument for the optimum quantity of money and the optimum money supply rule is, therefore, no longer applicable. To distinguish transactions services from money accords with Walras's crucial distinction between money as a stock and its services of availability as a flow.
\end{abstract}

Keywords: Recursive preferences, transaction services, marginal patience, optimum quantity of money, hyperneutrality

JEL classification: E2, E4, D9

\section{Introduction to the Neutrality Issue of Money}

How to capture the role of money in general equilibrium has long been debated. The controversy dates back to Walras (1874), Hicks (1935), and Patinkin (1956) (Bridel, 2002; Ostroy, 1989). Yet, money in the utility function has been a first-hand approach to address many macro-monetary issues. While it competes with more explicit theorising of money, e.g., to save transaction time (Baumol, 1952; Tobin, 1956), or to prepare against a stochastic process of payment and receipt (Patinkin, 1956, 1987) or to store value (Lucas, 1972; Samuelson, 1958), or to meet liquidity/cash-in-advance constraints (Clower, 1967), it has been argued that it is functionally equivalent to such explicit theorising under proper interpretations (Feenstra, 1986). ${ }^{1}$

a School of Business and Economics, Universiti Brunei Darussalam, Jalan Tungku Link, Gadong BE1410, Brunei Darussalam. Email: hiroaki.hayakawa@ubd.edu.bn

* The comments and suggestions from an anonymous referee are gratefully acknowledged.

1 Hayakawa (1994) demonstrated that if a cash-in-advance constraint (Clower, 1967) is reformulated along either the Baumol-Tobin transactions theory or McCallum's shopping time theory (McCallum, 1983), the Stockman-Abel type cash-in-advance model (Abel 1985; Stockman, 1981) is essentially equivalent to the Sidrauski model with money in the utility function (Sidrauski, 1967a, 1967b). This equivalence, however, is 
In particular, it has been argued à la Baumol (1952), Tobin (1956), and McCallum (1983) that money yields the so-called transaction services, and that such services can be measured by the amount of interest that agents are willing to forego on interestbearing assets. This argument, however, raises a fundamental question: Why do we not consider imputed transaction services in the utility function directly rather than entering money as a proxy for such services? The idea of imputed transaction services is more in line with Walras's insight that it is the marginal utility of such services that should be compared with the marginal utility of any other good in determining the quantity of money to hold (Bridel, 2002). This is evident in Walras's distinction between money as a stock and the "services of availability" (service d'approvisionnement) that money yields as a flow. Also, the violation of the Fisher equation due to the MundellTobin effect (Mundel, 1963; Tobin, 1965) is an indication that agents, under higher nominal interest rates, shift money to bonds to keep transaction services of money in line with consumption. The distinction is crucial in addressing how money affects real decisions and steady-state equilibrium.

We demonstrate that the imputed transaction services of real balances in the utility function bears drastically different implications for the neutrality of money. ${ }^{2}$ This issue, in neoclassical growth theory, dates back to Tobin (1965) and Johnson (1966) (Hayakawa, 1984, 1986), but it was Sidrauski (1967a, 1967b) who addressed it using a normative intertemporal model that features money in the utility function and a constant rate of time preference, and showed that money is superneutral. The issue is still widely debated from a number of different perspectives (e.g., Ascari, 1998; Epstein \& Hynes, 1983; Hayakawa, 1992, 1994; Homburg, 2015; Longaretti \& Gatti, 2004, 2006; Orphanides \& Solow, 1990; Rapach, 2003; Reis, 2007; Vaona, 2016; Wang, 2012). ${ }^{3}$ This paper gives another perspective to this literature by imputing the flow of transaction services of money and replacing money with this flow in the utility function. Agents

based on the assumption that time allocation tradeoffs are restricted to leisure and transaction time. He also demonstrated that if such tradeoffs are extended to include production time, money affects both the rate of time preference and the marginal productivity of capital. Also, with endogenous labour and capital, Wang and Yip (1992b) demonstrated that the three alternative approaches: money in the utility function, the cash-in-advance constraint, and the transactions cost, are qualitatively equivalent in that they yield similar comparative static results. Moreover, Patinkin (1956) introduced the real balance effects of money in the utility function, as a mechanism that restores equilibrium and reconciled Walrasian equilibrium with the presence of money (Bridel, 2002). This mechanism, however, has to be re-evaluated if money is replaced with transaction services.

2 Sidrauski (1967a) considers the flow of transaction services of real cash balances in the utility function, but he assumed that this flow is proportional to cash balances with the proportionality factor of one. Hence, his treatment of cash balances is essentially the same as money in the utility function.

3 Mundel (1963) and Tobin (1965) argued that an increase in the growth rate of money supply may raise the nominal interest rate by less than it increases the inflation rate since higher nominal interest rates increase the demand for bonds, thereby lowering real interest rates; see also Buyer and Hodrick (1982) on this effect. Such effects violate the Fisher equation. Sidrauski (1967a, 1967b), however, showed that money is superneutral, which was challenged by Epstein and Hynes (1983), Hayakawa (1992, 1994), Uzawa (1968), and others. The issue hinges on whether the rate of time preference is constant or affected by the monetary expansion. In more recent years, Ascari (1998) showed, under staggered wage setting, that monetary expansion has significant negative effects on steady state output and welfare. On the other hand, Rapach (2003) in his empirical study covering fourteen industrialised countries using a structural VAR model, reported that a permanent increase in inflation lowers the long-run real interest 
now respond to nominal interest rates by adjusting their holdings of real balances so as to keep the marginal rate of substitution between real balances and consumption unitary. That is, the quantity of real balances will adjust hyperbolically to keep this service flow in line with this condition. Such behaviour differs sharply from the case of money in the utility function.

One intriguing fact about money in the utility function can be illustrated in the Sidrauski model (1967a, 1967b), which exhibits that money is neutral to both steadystate real output and consumption, but not to real balance holdings. Because real balances fall with monetary expansion, the agent's welfare declines in steady state. But, if what is consumed is counted, namely, consumption and imputed transaction services, the agent's composite consumption (the sum of the two) actually increases. This is perplexing since agents are consuming more of this composite consumption. In a more restricted case, if the recursive preferences in the Sidrauski model are homothetic with an iso-elastic felicity function, the foregone nominal interest earnings are, as shown later, always kept proportional to consumption (e.g., Cohen, 1985). Therefore, neither physical consumption nor imputed transaction services are affected by the monetary expansion, hence leaving composite consumption unchanged. Yet, if money is an argument, the agent's welfare declines because real balance holdings fall. This problem can be avoided once transaction services replace money in the utility function.

This paper shows that transaction services, rather than money, yield entirely different implications for the neutrality of money as well as for the optimum quantity of money, and avoids the aforementioned problem of falling welfare. Specifically, we analyse a normative growth model in which agents have money illusion-free recursive preferences of a general class under endogenously varying time preferences, and demonstrate two propositions: (1) Money is hyperneutral in that both capital intensity (and consumption) and transaction services of real balances, hence the agent's welfare, are invariant to the monetary expansion. This neutrality holds whether the marginal impatience is increasing or decreasing. (2) Because of this invariance, Friedman's argument for the optimum quantity of money, which amounts to driving the marginal rate of substitution between money and consumption to zero, as well as for the optimal growth rate of money supply to achieve this condition is no longer valid. These propositions are obtained because the agents' optimal intertemporal decisions require

rate and increases the long-run output in many countries. In an endogenous growth context, however, Deev and Hodula (2016), employing a similar VAR model, confirmed the long-run superneutrality of money. Reis (2007), once again, studied the equilibrium dynamics of the Sidrauski model and reported both the neutral and non-neutral cases. Lioui and Poncet (2008) then showed that money is nonsuperneutral under the presence of uncertainty even if the utility function is separable in money and consumption, because the real interest rate is affected. Also, Wang (2012) analysed the case in which the time preference rate is given as a function of the real interest rate in the Sidrauski model, and showed that money is superneutral. On the other hand, Longaretti and Gatti $(2004,2006)$ approached the issue from the perspective of wealth, consumption, and bequests in the context of an overlapping generations model, and demonstrated that money is non-superneutral when agents are heterogeneous while it is superneutral when they are homogeneous. Vaona (2016) has written a survey article on anomalous empirical evidence about the superneutrality and the vertical long-run Phillips curve. Furthermore, Wang and Yip (1992a) reported in the context of endogenous growth that if money serves as a Hicks-neutral technological factor, money is superneutral to economic growth. 
that the marginal rate of substitution between real balances and consumption be unitary. They are obtained without imposing any particular assumption on the shape of the recursive preferences, and are in sharp contrast with what money in the utility function entails (Asako, 1983; Epstein \& Hynes, 1983; Friedman, 1969; Hayakawa, 1992).

The neutrality of money has a long history (Patinkin, 1987), and it has been debated in the context of both static and dynamic models, in reference to whether real and nominal variables can be dichotomised, or whether money is just a veil (Gale, 2010). Here we present a normative model, which closes the two conceivable channels for possible effect of money on agents' decisions: the wealth effect and the nominal interest rate effect. The model demonstrates that money is neutral to all real variables in steady state even including transaction services.

This finding is obtained whether the instantaneous discounting function is increasing or decreasing in consumption and real balances. Koopmans (1986, pp. 94-95) and Barro and Sala-i-Martin (1995, p. 109) were doubtful of the assumption of the increasing marginal impatience, and Becker and Mulligan (1997) addressed time preferences from the perspective of endogenous activities that are linked to future utilities through imagination and capital accumulation. The declining marginal impatience is opposed to what Uzawa (1968) and Koopmans (1960) assumed in earlier formulations. We show that the complete neutrality of money holds regardless of the nature of the marginal impatience. This is an important corollary to the neutrality demonstrated in this paper. ${ }^{4}$

\section{Analysis}

Consider the following decentralised setting: Output is produced by capital and labour according to a constant returns to scale (CRS) production function written in an intensive form as $f(k)$ where $k$ denotes capital intensity. The capital and labour markets are competitive, clearing at every moment of time; hence, the real interest rate $r(t)$ and the real wage rate $w(t)$ equal their marginal products.

$$
\begin{aligned}
& r(t)=f^{\prime}(k(t)) \\
& w(t)=f(k(t))-f^{\prime}(k(t)) k(t)
\end{aligned}
$$

Each agent, endowed with one unit of labour, supplies it inelastically to earn real wages, $w(t)$, at each time $t$. The agent's real asset holdings, $a(t)$, is comprised of capital, $k(t)$, and real balances, $m(t)$, and his income amounts to $r(t) a(t)+w(t)+\omega(t)$ (the monetary transfers from the government), which, after allowances are made for fertility $n$ and inflation $\pi(t)$, is distributed to consumption, $c(t)$, and asset accumulation,

4 There have been several attempts to examine the superneutrality under the assumption of decreasing marginal impatience. Gong (2006), for instance, showed that inflation reduces the resources oriented to the future and raises, thereby, the rate of time preference, which results in reduced capital stock. This result is opposite to what is obtained under increasing marginal impatience. Chen, Hsu and Lu (2011), on the other hand, examined, in the presence of a cash-in-advance constraint, the effect of higher monetary growth rates on capital, consumption and welfare in the long-run, and reported that Friedman's money supply rule does not apply, and confirmed the existence of a mild positive optimal inflation rate. 
$\dot{a}(t)$, where a dot over a variable denotes its time derivative. This defines the dynamic budget constraint.

$$
\dot{a}(t)=r(t) a(t)-n a(t)+w(t)+\omega(t)-i(t) m(t)-c(t)
$$

where $i(t)$ is the nominal interest rate equaling $r(t)+\pi(t)$. We impose the terminal boundary condition, which excludes Ponzi games:

$$
\lim _{t \rightarrow \infty} a(t) \exp \left[-\int_{0}^{\tau}[r(\tau)-n]\right]=0
$$

The agent is infinitely-lived. We assume that the agent's preferences are recursive à la Koopmans (1960) and that they are represented by a utility functional (Epstein, 1987a, b; Uzawa, 1968), without imposing any assumption on the nature of the marginal impatience (Becker and Mulligan, 1997). In general, if money-illusion is not precluded a priori, the functional is defined on the paths of consumption, nominal transaction services and the price level. The reason for considering transaction services in nominal terms is made clear shortly. We let $C, Q$ and $P$ denote these paths, respectively, with $c(t), q(t)$ and $p(t)$ representing their time $t$-images. With these notations, the functional we consider is written as:

$$
V(C, Q, P) \equiv \int_{0}^{\infty} u(c(t), q(t), p(t)) \exp \left[-\int_{0}^{t} \vartheta(c(\tau), q(t), p(\tau)) d \tau\right] d t
$$

where $u(c(t), q(t), p(t))$ and $\vartheta(c(t), q(t), p(t))$ are referred to as the instantaneous utility and discounting functions, respectively. We now impose that the functional is moneyillusion free in the sense that simultaneous doubling of the paths of money holdings and the price level leaves the value of the functional unchanged. That is,

$$
V(C, \lambda Q, \lambda P)=V(C, Q, P)
$$

Clower and Riley (1976), Dusansky and Kalman (1974, 1976), and Wichers (1976) discussed the issue of money-illusion in the context of static consumer theory. Ours is a dynamic extension of their argument.

The assumption that the utility functional we consider is money-illusion free amounts to assuming that the instantaneous utility and discounting functions are homogeneous of degree zero in nominal transaction services and the price level. That is,

$$
\begin{aligned}
& u(c, q, p)=u(c, x, 1) \equiv v(c, x) \\
& \vartheta(c, q, p)=\vartheta(c, x, 1) \equiv \delta(c, x) \text { where } x=q / p
\end{aligned}
$$

Here, we measure nominal transaction services, $q$, by nominal interest earnings, $i M$, where $i$ is the nominal interest rate and $M$ is money holdings in nominal terms. With this measurement, $x$ equals $i m$ where $m=M / p$. A path of transaction services in real terms shall be denoted by $X$. 
In terms of $v(c, x)$ and $\delta(c, x)$, the money-illusion free functional is written as:

$$
U(C, X) \equiv \int_{0}^{\infty} v(c(t), x(t)) \exp \left[-\int_{0}^{t} \delta(c(\tau), x(\tau)) d \tau\right] d t
$$

In the sequel, the functions, $v(c(t), x(t))$ and $\delta(c(\tau), x(\tau))$, are assumed to be positive and twice continuously differentiable; they are also strictly concave and convex, respectively. While the function $v(c(t), x(t))$ is assumed to have positive partial derivatives, the discounting function $\delta(c(\tau), x(\tau))$ can have positive or negative partial derivatives depending on whether the marginal impatience is increasing or decreasing. Also, consumption and transaction services are assumed to be Edgeworth-complementary in both functions; that is, $v_{c m}(c, x)>0$ and $\delta_{c m}(c, x)>0$.

In characterising the optimality conditions below, we shall make use of the righthand tail paths of consumption and transaction services. These are the paths that are obtained by advancing the original paths, $C$ and $X$, by $t$ units of time. Formally, they are the paths whose time $\tau$-images equal $c(t+\tau)$ and $m(t+\tau)$. We denote them by ${ }_{t} C$ and ${ }_{t} X$. For such paths, the functional (1) gives:

$$
\begin{aligned}
U\left({ }_{t} C,{ }_{t} X\right) & \equiv \int_{0}^{\infty} v(c(t+\tau), x(t+\tau)) \exp \left[-\int_{0}^{\tau} \delta(c(t+s), x(t+s)) d s\right] d \tau \\
& =\int_{t}^{\infty} v(c(\tau), x(\tau)) \exp \left[-\int_{t}^{\tau} \delta(c(s), x(s)) d s\right] d \tau
\end{aligned}
$$

The optimal paths of consumption and transaction services are determined by solving the following optimisation problem:

$$
\operatorname{Max}(U, X)=\int_{0}^{\infty} v(c(t), x(t)) y(t) d t
$$

subject to:

$$
\begin{aligned}
& x(t)=i(t) m(t) \\
& \dot{y}(t)=-\delta(c(t), x(t)) y(t) \\
& \dot{a}(t)=r(t) a(t)-n a(t)+w(t)+\omega(t)-x(t)-c(t)
\end{aligned}
$$

The initial conditions: $y(0)=1$ and $a(0)=a_{0}$ (given)

where the paths of the real interest, the wage rate, and the inflation rate are given as $\{r(\tau)\}_{\tau=0}^{\infty},\{w(\tau)\}_{\tau=0}^{\infty}$, and $\{\pi(\tau)\}_{\tau=0}^{\infty}$, respectively. With the nominal interest defined as $i(t)=r(t)+\pi(t)$, its path $\{i(\tau)\}_{\tau=0}^{\infty}$ is known from the paths of the real interest rate and the inflation rate. Also, the expected path of the monetary transfers from the government, $\{\omega(\tau)\}_{\tau=0}^{\infty}$, is given at the outset. Foresight is assumed to be perfect. 
With $x(t)=i(t) m(t)$ substituted in, we may rewrite the optimisation problem as:

$\operatorname{Max} U(C, M)=\int_{0}^{\infty} v(c(t), i(t) m(t)) y(t) d t$

subject to:

$\dot{y}(t)=-\delta(c(t), i(t) m(t)) y(t)$

$\dot{a}(t)=r(t) a(t)-n a(t)+w(t)+\omega(t)-i(t) m(t)-c(t)$

The initial conditions: $y(0)=1$ and $a(0)=a_{0}$ (given).

We write the Hamiltonian of this problem as:

$$
\begin{aligned}
& H[c(t), m(t) ; \lambda(t), \mu(t)] \\
& \quad \equiv y(t)[v(c(t), i(t) m(t))-\lambda(t) \delta(c(t), i(t) m(t))] \\
& \quad+\mu(t)\{r(t) a(t)-n a(t)+w(t)+\omega(t)-i(t) m(t)-c(t)\}
\end{aligned}
$$

where $\lambda(t)$ and $\mu(t)$ are the costate variables of $y(t)$ and $a(t)$. Prontryagin's maximum principle yields the following optimality conditions:

$$
\begin{aligned}
& y(t)\left[v_{c}(c(t), i(t) m(t))-\lambda(t) \delta_{c}(c(t), i(t) m(t))\right]=\mu(t) \\
& y(t)\left[v_{m}(c(t), i(t) m(t))-\lambda(t) \delta_{m}(c(t), i(t) m(t))\right] i(t)=\mu(t) i(t) \\
& \dot{\lambda}(t)=-\frac{\partial H(t)}{\partial y(t)}=-[v(c(t), i(t) m(t))-\lambda(t) \delta(c(t), i(t) m(t))] \\
& \dot{\mu}(t)=-\frac{\partial H(t)}{\partial a(t)}=-[r(t)-n] \mu(t)
\end{aligned}
$$

The transversality conditions are:

$$
\begin{aligned}
\lim _{t \rightarrow \infty} y(t) \lambda(t) & =0 \\
\lim _{t \rightarrow \infty} \mu(t) a(t) & =\lim _{t \rightarrow \infty} y(t)\left[v_{c}(c(t), i(t) m(t))-\lambda(t) \delta_{c}(c(t), i(t) m(t))\right] a(t) \\
& =\lim _{t \rightarrow \infty} y(t)\left[v_{m}(c(t), m(t))-\lambda(t) \delta_{m}(c(t), m(t))\right] a(t)=0
\end{aligned}
$$

The solution of the differential equation (21) is given by:

$$
\lambda(t)=\int_{t}^{\infty} v(c(\tau), i(t) m(\tau)) \exp \left[-\int_{t}^{\tau} \delta(c(s), i(t) m(s)) d s\right] d \tau=U\left({ }_{t} C,{ }_{t} X\right)
$$

This solution implies that the transversality condition (23) requires that the present discounted value of the future life-time utility vanish in the indefinite future. 
With (25) substituted in and with (22) integrated, conditions (19)-(22) are consolidated as (along with condition (23)):

$$
\begin{aligned}
& y(t)\left[v_{c}(c(t), i(t) m(t))-U\left({ }_{t} C,{ }_{t} X\right) \delta_{c}(c(t), i(t) m(t))\right]=\mu(t) \\
& y(t)\left[v_{m}(c(t), i(t) m(t))-U\left({ }_{t} C,{ }_{t} X\right) \delta_{m}(c(t), i(t) m(t))\right] i(t)=\mu(t) i(t) \\
& \mu(t)=\mu(0) \exp \left\{-\int_{0}^{t}[r(\tau)-n] d \tau\right\} \\
& \lim _{t \rightarrow \infty} \mu(t) a(t) \\
& =\lim _{t \rightarrow \infty} y(t)\left[v_{c}(c(t), i(t) m(t))-U\left({ }_{t} C,{ }_{t} X\right) \delta_{c}(c(t), i(t) m(t))\right] a(t) \\
& \left.=\lim _{t \rightarrow \infty} y(t)\right)\left[v_{m}(c(t), i(t) m(t))-U\left({ }_{t} C,{ }_{t} X\right) \delta_{m}(c(t), i(t) m(t))\right] a(t)=0
\end{aligned}
$$

The optimality requires that the marginal utility of consumption and real balances in the Volterra derivative sense on the left side of (26) and (27) be equal to the implicit utility value of the marginal value of time $t$-assets with respect to consumption and real balances on the right side; see Epstein (1987a, b), Volterra (1959) and Wan (1970) for Volterra derivatives, and Hayakawa and Ishizawa $(1993,1997)$ for the economic meaning of conditions (26) and (27). By condition (28), the marginal utility of time $t$-assets declines at rate $r(t)-n$ from its initial value $\mu(0)$. The transversality condition (29) states that the utility value of the stock of real assets where the marginal utility of time $t$-assets is used as its implicit utility price vanishes in the indefinite future.

Notice that since the nominal interest rate appears on both sides of (27), it can be cancelled. Hence, (27) takes the same form as (26), which indicates that in real terms, real balances cost as much as consumption; this is so because what one pays for interest foregone can be converted to consumption one-to-one. Taking the ratio of conditions (26) and (27) shows that the temporal marginal rate of substitution between real balances and consumption is unitary. That is, with $x(t)=i(t) m(t)$ substituted in,

$$
\frac{v_{c}(c(t), x(t))-U\left({ }_{t} C,{ }_{t} X\right) \delta_{c}(c(t), x(t))}{v_{m}(c(t), x(t))-U\left({ }_{t} C,{ }_{t} X\right) \delta_{m}(c(t), x(t))}=1
$$

This condition shows that at each moment, transaction services measure by $x(t)=$ $i(t) m(t)$ and consumption are related implicitly by some function $G$ :

$$
G\left(x(t), c(t), U\left({ }_{t} C,{ }_{t} X\right)\right)=0
$$

Solving this for $x(t)$ gives:

$$
x(t) \equiv i(t) m(t)=F\left[c(t), U\left({ }_{t} C,{ }_{t} X\right)\right]
$$

With this relationship taken into account, the Keynes-Ramsey rule of consumption is obtained as follows: First, taking the logarithmic time derivative of (26) gives: 


$$
-\rho^{c}(t)+\xi^{c c} \frac{\dot{c}}{c}+\xi^{c x} \frac{\dot{x}}{x}=-[r(t)-n]
$$

where

$$
\begin{aligned}
& \xi^{c c}\left(c(t), x(t), U\left({ }_{t} C,{ }_{t} X\right) \equiv \frac{\left[v_{c c}-\delta_{c c} U\left({ }_{t} C,{ }_{t} X\right)\right] c}{v_{c}-\delta_{c} U\left({ }_{t} C,{ }_{t} X\right)}\right. \\
& \xi^{c x}\left(c(t), x(t), U\left({ }_{t} C,{ }_{t} X\right) \equiv \frac{\left[v_{c x}-\delta_{c x} U\left({ }_{t} C,{ }_{t} X\right)\right] x}{v_{c}-\delta_{c} U\left({ }_{t} C,{ }_{t} X\right)}\right. \\
& \rho^{c}\left(c(t), x(t), U\left({ }_{t} C,{ }_{t} X\right)\right) \equiv \frac{\delta_{c} v-\delta v_{c}}{v_{c}-\delta_{c} U\left({ }_{t} C,{ }_{t} X\right)}
\end{aligned}
$$

where $\xi^{c c}$ is the elasticity of the marginal utility of consumption with respect to consumption; $\xi^{c x}$ is the elasticity of the marginal utility of consumption with respect to transaction services; $\rho^{c}$ is the rate of time preference based on the marginal utility of consumption; see footnote 5 for the derivation of $\rho^{c .5}$

In a similar manner, taking the logarithmic time derivative of (27) gives:

$$
\begin{aligned}
& \frac{\dot{x}}{x}=\varepsilon \frac{\dot{c}}{c}-\frac{F_{U}}{F}\left[v(c, x)-\delta(c, x) U\left({ }_{t} C,{ }_{t} X\right)\right] \\
& \text { where } \varepsilon \equiv \frac{F_{c} c}{F} ; F_{c} \text { and } F_{U} \text { are the partial derivatives of function } F \text {. }
\end{aligned}
$$

With (34) substituted into (33), the Keynes-Ramsey rule of consumption is obtained as:

$$
\begin{aligned}
\frac{\dot{c}}{c} & =-\frac{1}{\xi^{c c}+\xi^{c x} \varepsilon}[r(t)-n-\rho(t)]+\frac{\xi^{c x}}{\xi^{c c}+\xi^{c x} \varepsilon} \frac{F_{U}}{F}\left[v(c, x)-\delta(c, x) U\left({ }_{t} C,{ }_{t} X\right)\right] \\
& \equiv \Gamma\left[c(t), x(t), U\left({ }_{t} C,{ }_{t} X\right) ; r(t)\right]
\end{aligned}
$$

And, with this substituted into (34), the Keynes-Ramsey rule of transaction services is obtained as:

$$
\begin{aligned}
\frac{\dot{x}}{x}= & -\frac{\varepsilon}{\xi^{c c}+\xi^{c x} \varepsilon}[r(t)-n-\rho(t)]+\left[\frac{\varepsilon \xi^{c x}}{\xi^{c c}+\xi^{c x} \varepsilon}-1\right] \frac{F_{U}}{F}[v(c, x) \\
& \left.-\delta(c, x) U\left({ }_{t} C,{ }_{t} X\right)\right]
\end{aligned}
$$

5 The instantaneous rate of change of the marginal rate of substitution of consumption between $t$ and $t^{\prime}$, evaluated along locally constant paths of consumption and transaction services (i.e., along paths where $\dot{c}(t)=\dot{x}(t)=0$ at the point of measurement), defines the rate of time preference at time $t$, denoted by $\rho^{c}(t ; C, X)$

$$
\begin{aligned}
\rho^{c}(t ; C, X) & \left.\equiv \frac{d}{d t^{\prime}} \log M R S^{c}\left(t, t^{\prime} ; C, X\right)\right|_{t^{\prime}=t, \dot{c}(t)=\dot{x}(t)=0} \\
& =\frac{v_{c}(c(t), x(t)) \delta(c(t), x(t))-v(c(t), x(t)) \delta_{c}(c(t), x(t))}{v_{c}(c(t), x(t))-\delta_{c}(c(t), x(t)) U\left({ }_{t} C,{ }_{t} X\right)}
\end{aligned}
$$

See Hayakawa (1991) for the equivalence between the Böhm-Bawerkian and Fisherian rates of time preference. 
To see how consumption is related to wealth, we integrate the budget constraint (14) from time $t$ to $\infty$ under the terminal boundary condition (4).

$$
\begin{aligned}
& \int_{t}^{\infty} c(s) \exp \left\{-\int_{t}^{s}[r(\tau)-n] d \tau\right\} d s+\int_{t}^{\infty} x(t) \exp \left\{-\int_{t}^{s}[r(\tau)-n] d \tau\right\} d s \\
& =a(t)+h(t)+T(t)
\end{aligned}
$$

where

$$
\begin{aligned}
& h(t) \equiv \int_{t}^{\infty} w(t) \exp \left\{-\int_{t}^{s}[r(\tau)-n] d \tau\right\} d s \\
& T(t) \equiv \int_{t}^{\infty} \omega(t) \exp \left\{-\int_{t}^{s}[r(\tau)-n] d \tau\right\} d s
\end{aligned}
$$

$h(t)$ is the human wealth defined as the present discounted value of the stream of wage earnings, and $T(t)$ is the present discounted value of the stream of the monetary transfers. Then, with (35) integrated from time $t$ to any arbitrary time $s$ where $s>t$, consumption at time $s$ is related to consumption at time $t$ through:

$$
c(s)=c(t) \exp \left\{\int_{t}^{s} \Gamma\left[c(\tau), x(\tau), U\left({ }_{\tau} C,{ }_{\tau} X\right) ; r(\tau)\right] d \tau\right\} d s
$$

With (38) substituted into (37), consumption at time $t$ is related to wealth at time $t$ as:

$$
\begin{aligned}
& c(t)=\frac{1}{\left.\int_{t}^{\infty} \exp \left\{\int_{t}^{s} \Gamma\left[c(\tau), x(\tau), U\left({ }_{\tau} C,{ }_{\tau} X\right) ; r(\tau)\right]-[r(\tau)-n]\right\} d \tau\right\} d s} W(t) \\
& \text { where } W(t) \equiv a(t)+h(t)+T(t)-\int_{t}^{\infty} x(s) \exp \left\{-\int_{t}^{s}[r(\tau)-n] d \tau\right\} d s
\end{aligned}
$$

$W(t)$ can be decomposed into two parts, real and monetary. They are defined as:

$$
\begin{aligned}
& W_{r}(t) \equiv k(t)+h(t) \\
& W_{m}(t) \equiv m(t)+T(t)-\int_{t}^{\infty} x(t) \exp \left\{-\int_{t}^{s}[r(\tau)-n] d \tau\right\} d s
\end{aligned}
$$

Because the monetary component, as shown in footnote 6 , vanishes under the terminal boundary condition (which excludes Ponzi games) ${ }^{6},(39)$ is reduced to:

6 The fact that the monetary wealth vanishes under the no-Ponzi game condition can be shown as follows. Consider the time $t$-discounted value of the stock of real balances held at some future point in time, say, time s, i.e.,

$$
\exp \left\{-\int_{t}^{s}[r(\tau)-n] d \tau\right\} \frac{M(s)}{P(s) L(s)}
$$

To see how much this value changes as $s$ is changed, take the derivative of this quantity with respect to $s$, which gives: 


$$
c(t)=\alpha(t) W_{r}(t)
$$

where

$$
\alpha(t) \equiv \frac{1}{\int_{t}^{\infty} \exp \left\{\int_{t}^{s} \Gamma\left[c(\tau), x(\tau), U\left({ }_{\tau} C,{ }_{\tau} X\right) ; r(t)\right]-[r(t)-n] d \tau\right\} d s}
$$

And, with (42) substituted in (32), it follows that:

$$
x(t)=F\left[\alpha(t) W_{r}(t), U\left({ }_{t} C,{ }_{t} X\right)\right]
$$

We note that (42) shows that the coefficient $\alpha(t)$ is not affected by the path of the nominal interest rate, or, more precisely, by the path of its time rate of change. This shows that with transaction services directly considered in the utility functional, the transmission channel of money through the changing nominal interest rates is not working, which contrasts with the case in which real balances enter the utility function. In the latter case, the channel of the changing nominal interest rates remains operating as it shows up in $\alpha(t)$ (Cohen, 1985; Fischer, 1979). In neither case, money affects consumption through wealth effects since the monetary wealth vanishes.

\section{Steady State}

We now turn to steady state analysis. With $r(t)=f^{\prime}(k)$ substituted in, the dynamics of the system in $c, x$, and $k$ is governed by (44), (45), and the output market equilibrium condition (46). That is,

$$
\begin{aligned}
& \frac{\dot{c}}{c}=-\frac{1}{\xi^{c c}+\xi^{c x} \varepsilon}\left[f^{\prime}(k(t))-n-\rho(t)\right]+\frac{\xi^{c x}}{\xi^{c c}+\xi^{c x} \varepsilon} \frac{F_{U}}{F}\left[v(c, x)-\delta(c, x) U\left({ }_{t} C,{ }_{t} X\right)\right] \\
& \frac{\dot{x}}{x}=\varepsilon \frac{\dot{c}}{c}-\frac{F_{U}}{F}\left[v(c, x)-\delta(c, x) U\left({ }_{t} C,{ }_{t} X\right)\right] \\
& \dot{k}=f(k)-n k-c \\
& \frac{d}{d s}\left[\exp \left\{-\int_{t}^{s}[r(\tau)-n] d \tau\right\} \frac{M(s)}{P(s) L(s)}\right] \\
& =\omega(s) \exp \left\{-\int_{t}^{s}[r(\tau)-n] d \tau\right\}-i(s) m(s) \exp \left\{-\int_{t}^{s}[r(\tau)-n] d \tau\right\}
\end{aligned}
$$

where $\omega(s)=\left(\frac{\dot{M(s)}}{P(s) L(s)}\right)$. This shows that the time $t$-value of $m(s)$ changes at the rate equalling the difference between the time $t$-value of the monetary transfers from the government and the same time $t$-value of the holding cost of $m(s)$. Taking the lifetime total of such changes by integrating them from time $t$ to $\infty$ and imposing the condition: $\lim _{s \rightarrow \infty} m(s) \exp \left\{-\int_{t}^{s}[r(\tau)-n] d \tau\right\}=0$, which follows from the terminal boundary condition (4), we see that the monetary wealth vanishes.

$$
W_{m}(t) \equiv m(t)+T(t)-\int_{t}^{\infty}[r(s)+\pi(s)] m(s) \exp \left\{-\int_{t}^{s}[r(\tau)-n] d \tau\right\} d s=0
$$


In steady state, $U\left({ }_{t} C,{ }_{t} X\right)$ equals $v(c, x) / \delta(c, x)$. Hence, the term $v(c, x)-\delta(c, x) U\left({ }_{t} C\right.$, $\left.{ }_{t} X\right)$ vanishes; i.e.,

$$
v(c, x)-\delta(c, x) U\left({ }_{t} C,{ }_{t} X\right)=v(c, x)-\delta(c, x) \frac{v(c, x)}{\delta(c, x)}=0
$$

Moreover, the rate of time preference reduces to $\delta(c, x)$ in steady state.

$$
\rho\left(c(t), x(t), U\left({ }_{t} C,{ }_{t} X\right)\right)=\frac{v_{c} \delta-v \delta_{c}}{v_{c}-\delta_{c} U\left({ }_{t} C,{ }_{t} X\right)}=\delta(c, x)
$$

Therefore, steady state is characterised by the following two conditions:

$$
\begin{aligned}
& \delta\left(c^{*}, x^{*}\right)=f^{\prime}\left(k^{*}\right)-n \\
& c^{*}=f\left(k^{*}\right)-n k^{*}=\left[f^{\prime}\left(k^{*}\right)-n\right] W_{r}^{*}
\end{aligned}
$$

$$
\text { where } W_{r}^{*}=\left[f\left(k^{*}\right)-n k^{*}\right] /\left[f^{\prime}\left(k^{*}\right)-n\right]
$$

where the asterisk denotes steady state. ${ }^{7}$ Thus, the rate of time preference equals the (net) marginal product of capital, and consumption settles at the level of the (net) real interest return on real wealth, which amounts to net output $f\left(k^{*}\right)-n k^{*}$.

7 Because of the condition that the marginal rate of substitution between consumption and real balances equals one when the transaction services of real balances enter the utility function (condition (30)), the dynamics is reduced to a system of two differential equations:

$$
\begin{aligned}
\dot{k} & =f(k)-n k-c \\
\frac{\dot{c}}{c} & =-\frac{1}{\xi^{c c}+\xi^{c x} \varepsilon}[r(t)-n-\rho(t)]+\frac{\xi^{c x}}{\xi^{c c}+\xi^{c x} \varepsilon} \frac{F_{U}}{F}\left[v(c, x)-\delta(c, x) U\left({ }_{t} C,{ }_{t} X\right)\right] \\
& \equiv \Gamma\left\{c(t), F\left[c(t), U\left({ }_{t} C,{ }_{t} X\right)\right], U\left({ }_{t} C,{ }_{t} X\right)\right\}
\end{aligned}
$$

The Jacobian matrix $J$ for this system is given as:

$$
J=\left[\begin{array}{ll}
a_{11} & a_{12} \\
a_{21} & a_{22}
\end{array}\right]=\left[\begin{array}{cc}
f^{\prime}(k)-n & -1 \\
0 & -\frac{1}{\xi^{c c}+\xi^{c x} \varepsilon} \frac{\partial \rho}{\partial c}+\frac{\xi^{c x}}{\xi^{c c}+\xi^{c x} \varepsilon} \frac{F_{U}}{F}\left[v_{c}(c, x)-\delta_{c}(c, x) U\left({ }_{t} C,{ }_{t} X\right)\right]
\end{array}\right]
$$

With respect to the term $a_{22}$, evaluating $\partial \rho / \partial c$ (where $\rho=\left[v_{c} \delta-v \delta_{c}\right] /\left[v_{c}-\delta_{c} U\left({ }_{t} C,{ }_{t} X\right)\right]$ at steady state by making use of $U=v / \delta$, we see that it equals zero. Likewise, $F_{U}$ at steady state is negative. Hence, the sign of $a_{22}$ depends on the sign of $\left(\xi^{c x} /\left(\xi^{c c}+\xi^{c x} \varepsilon\right)\right.$, which, in view of $F_{U}<0$, has to be positive in order to obtain a stable saddle. We know from our assumption that $v(c, m)$ is strictly concave while $\delta(c, m)$ is strictly convex; hence, $v_{c c}<0$ and $\delta_{c c}>0$, which implies that $\xi^{c c}$ is negative. Therefore, the only case that makes the saddle-point stability possible is the one in which $\xi^{c x}<0$ and $\xi^{c c}+\xi^{c x} \varepsilon<0$ where $\varepsilon\left(\equiv F_{c} c / F\right)$ can be demonstrated to be negative in steady state. The case $\xi^{c x}>0$ is excluded as this makes $\xi^{c x} /\left(\xi^{c c}+\right.$ $\left.\xi^{c x} \varepsilon\right)$ positive, hence the determinant of the Jacobian matrix positive, with two eigenvalues taking positive values, which makes the critical point an unstable node. In our model, $k$ (capital) is a state variable that moves from an initially given value; this variable corresponds with a negative eigenvalue, whereas consumption $c$ is a jump variable, which corresponds with a positive eigenvalue. On stability in the saddlepoint sense, see Chen, Hsu and Lu (2008), Groth (2017, Ch. 10 for the Ramsey model and Ch. 17 for the Sidrauski model), Levhari and Liviatan (1972), and Sidrauski (1967a). 
By (32), transaction services in steady state, $x^{*}=i^{*} m^{*}$, is related to steady state consumption through:

$$
x^{*}(t)=F\left[c^{*}, u\left(c^{*}, x^{*}\right) / \delta\left(c^{*}, x^{*}\right)\right]
$$

which gives $x^{*}$ as a function of $c^{*}$.

$$
x^{*}=\phi\left(c^{*}\right)
$$

With this taken into account, the steady-state rate of time preference $\delta\left(c^{*}, x^{*}\right)$ equals $\delta\left(c^{*}, \phi\left(c^{*}\right)\right)$. Moreover, since steady-state consumption and capital are related through:

$$
c^{*}=C\left(k^{*}\right) \equiv f\left(k^{*}\right)-n k^{*}
$$

the steady-state rate of time preference can be expressed as a function of only steadystate capital intensity.

$$
\delta\left(c^{*}, \phi\left(c^{*}\right)\right)=\delta\left(C \left(k^{*}, \phi\left(C\left(k^{*}\right)\right)\right.\right.
$$

Graphically, the steady-state capital intensity can be represented by the intersection of the two schedules, one representing the rate of time preference and the other representing the net marginal product of capital (as condition (49) indicates). This is shown in Figure 1.

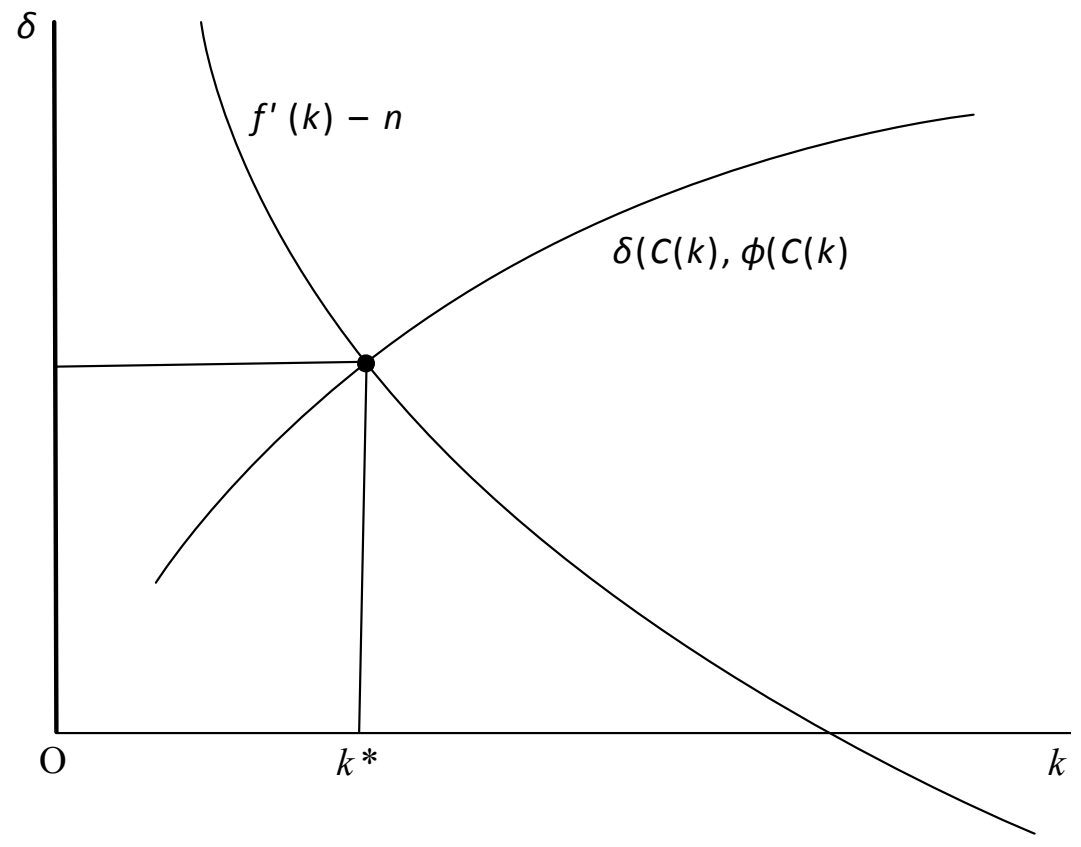

Figure 1. Net marginal product of capital and the rate of time preference Note: Because the net marginal product of capital and the rate of time preference (as of steady state) are functions of only the capital intensity, both are invariant to the monetary expansion. 
Because steady state consumption equals $f\left(k^{*}\right)-n k^{*}$ and since steady state transaction services are determined as $x^{*}=\phi\left(c^{*}\right)$, both are invariant to the monetary expansion. The reason is clear: How much to hold of real balances for the transaction services is a real decision based on the marginal rate of substitution between such services and consumption, which is unitary as condition (30) shows. Furthermore, because the steady-state welfare is given by $v\left(c^{*}, x^{*}\right) / \delta\left(c^{*}, x^{*}\right)$, the invariance of $k^{*}$ and $x^{*}$ to the monetary expansion implies that the steady-state welfare of the agent is also invariant to this expansion. Thus, we see that money is hyperneutral, that is, completely neutral to capital intensity, consumption, transaction services, and welfare in steady state regardless of the nature of the marginal impatience.

\section{Comparison with Money in the Utility Function}

We now compare these results of hyperneutrality with the case of money in the utility function. For a class of recursive preferences that allow the rate of time preference to vary endogenously, Epstein and Hynes (1983) demonstrated, under increasing marginal impatience, that the monetary expansion is no longer neutral to steady-state capital intensity. The rationale for this non-superneutrality lies in the fact that as real balance holdings decline in response to the higher monetary expansion, the steady-state rate of time preference falls, so that steady-state capital intensity increases to lower the net marginal product of capital. Because the instantaneous utility function, in their analysis, is a constant function set at minus one, the steady-state welfare given by $-1 / \delta\left(c^{*}, m^{*}\right)$ falls in response to the monetary expansion. If the instantaneous utility function is given a more general specification, the monotonicity assumption on preferences, which amounts to saying that the higher steady-state paths are preferred to the lower ones, assures a fall in welfare. While this outcome is important, it remains ambiguous whether the agent consumes more transaction services or less in response to the monetary expansion because to what extent real balance holdings decline depends on the marginal rate of substitution between such balances and consumption.

Epstein and Hynes's case is illustrated in Figure 2, where a fall in real balance holdings shifts the steady-state-rate-of-time-preference schedule downward, so that the steady-state capital intensity shifts from point A to point B along the net-marginalproduct-of-capital schedule. Therefore, the greater is the fall in steady-state real balances, the greater is the rise in steady-state capital intensity.

It is possible for steady-state welfare to remain unchanged with a higher rate of monetary expansion. The case in point happens when real balances and consumption are complementary while time preferences are held rigid (Asako 1983). In this case, the instantaneous utility function takes a Leontief form with its indifference curves having right angle kinks. For such indifference curves, a change in the nominal interest rate produces no resulting change in the ratio of consumption and real balances. Both consumption and real balances are, therefore, invariant to monetary expansion. This strong superneutrality is also observed in a more general case in which the rate of time preference changes endogenously (Hayakawa, 1992, 1994). Thus, regardless of the variability of the rate of time preference, it is possible for steady-state welfare not to be affected by the monetary expansion. 


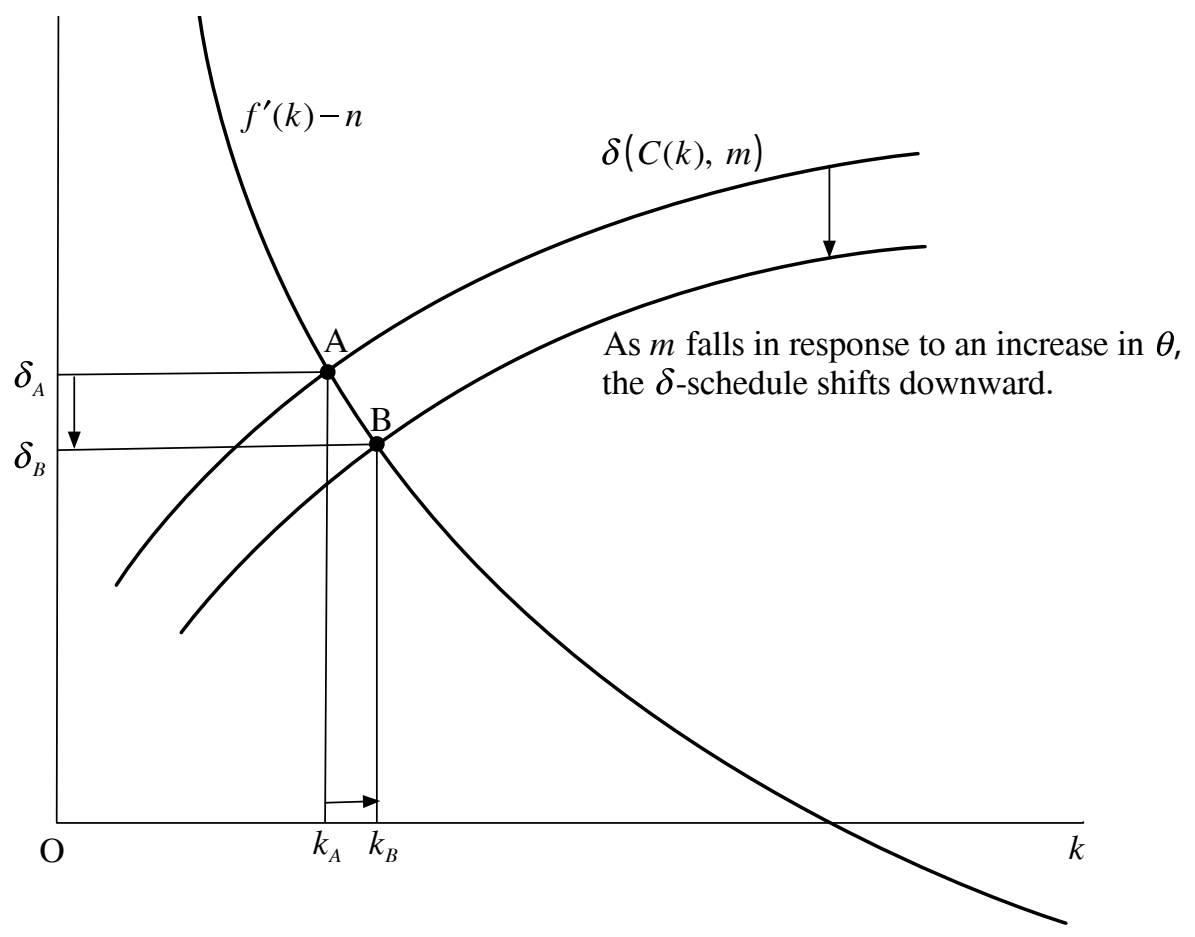

Figure 2. Epstein and Hynes's case

Note: A higher rate of monetary expansion shifts the rate-of-time-preference schedule downward, which results in an increase in the steady-state capital intensity. Money is, therefore, non-superneutral.

The complementary case, or the more general case referred to above, raises a question. Because, in such cases, the agent holds the same amount of real balances in the face of a higher monetary expansion rate, transaction services measured by foregone nominal interest returns must go up. If so, the agent's composite consumption (consumption and transaction services combined) increases. Yet, this increase in composite consumption cannot affect the steady-state welfare since it is only a change in real balance holdings that affects the agent's utility when money enters the utility function.

There is still another case that makes the same point. In the recursive preferences considered here, let the instantaneous utility function be iso-elastic while the instantaneous discounting rate remains fixed. Such a stipulation is a special case of homothetic preferences. We write the utility functional as:

$$
\int_{0}^{\infty} \frac{1}{1-\zeta}\left[c(t)^{1-\sigma} m(t)^{\sigma}\right]^{1-\zeta} y(t) d t
$$

The optimality conditions corresponding to (19) and (20) are given by:

$$
y(t)\left[\left(c(t)^{1-\sigma} m(t)^{\sigma}\right)^{-\zeta}(1-\sigma) c(t)^{-\sigma} m(t)^{\sigma}\right]=\mu(t)
$$




$$
y(t)\left[\left(c(t)^{1-\sigma} m(t)^{\sigma}\right)^{-\zeta} \sigma c(t)^{1-\sigma} m(t)^{\sigma-1}\right]=\mu(t) i(t)
$$

Taking the ratio of these conditions yields,

$$
\frac{\sigma}{1-\sigma} \frac{c(t)}{m(t)}=i(t)
$$

This condition shows that the imputed transaction services $i(t) m(t)$ amount to a fixed proportion of consumption; i.e.,

$$
i(t) m(t)=\frac{\sigma}{1-\sigma} c(t)
$$

Because steady-state consumption depends only on the fixed rate of time preference $\delta$, hence invariant to the monetary expansion, steady state transaction services also remain invariant to this expansion. Thus, with such homothetic preferences, the monetary expansion affects neither consumption nor transaction services. The invariance of the imputed transaction services implies that as the monetary expansion raises the nominal interest rate, real balance holdings fall hyperbolically to keep such services unchanged. Yet, steady-state welfare falls because real balances enter the utility function. Thus, in response to the monetary expansion, in steady state, consumption and composite consumption remain invariant, real balances fall and welfare declines. Such an outcome contrasts with what is obtained when transaction services enter the utility function, for in this alternative approach the monetary expansion leaves capital intensity, consumption, transaction services, composite consumption and welfare unchanged in steady state.

\section{The Optimum Quantity of Money and the Optimum Growth of Money Supply}

Treating transaction services in the utility function has an important bearing on Friedman's optimum quantity of money (Friedman, 1969). As shown above, neither capital intensity nor transaction services is affected by the monetary expansion in steady state; it, therefore, follows that steady-state welfare remains unaffected. If so, Friedman's idea of the optimum quantity of money based on welfare considerations no longer applies. If, for example, money is contracted at the rate of real interest rate to induce a fall in the expected inflation rate so that the cost of holding real balances is minimised, real balance holdings will increase, but transaction services (measured by foregone nominal interest) remain the same, hence welfare is not affected. Friedman's idea retains its relevance when money enters the utility function, but loses its applicability when the imputed transaction services enter the same function.

To illustrate this point between the two cases, consider again a particular specification of the utility functional (1) where the instantaneous utility function is set at minus one and the instantaneous discounting function is a function of consumption and transaction services, under increasing marginal impatience in consumption and real balances. For such a functional, steady-state welfare is ranked by $\delta(c, x)$. Steadystate capital intensity $k^{*}$ is determined at the intersection of the two schedules, one 
representing the rate of time preference $\delta(C(k), \phi(C(k))$ and the other representing the net marginal product of capital $f^{\prime}(k)-n$. Consumption settles at level $c^{*}=C\left(k^{*}\right)$ and transaction services at level $x^{*}=\phi(C(k))$. The agent's steady state welfare, therefore, amounts to $-1 / \delta(C(k), \phi(C(k))$, which is independent of the monetary expansion. Thus, varying the growth rate of money supply has no bearing on the searching of the optimum real balance holdings.

If, on the other hand, real balances enter the utility function instead, the steadystate welfare is given by $-1 / \delta(c, m)$, hence, ranked by $\delta(c, m)$ (i.e., the higher the value of $\delta(c, m)$, the higher the steady state welfare (measured by a negative number). The optimum steady-state levels of real balances and consumption have to be determined simultaneously by maximising $\delta(c, m)$ subject to the Fisherian condition: $\delta(c, m)=$ $f^{\prime}(K(c))-n$.

$\max \delta(c, m)$

subject to: $\delta(c, m)=f^{\prime}(K(c))-n$

where $k=K(c)$ is the inverse function of $c=C(k)$ to the left of the Golden rule path.

The optimality requires:

$$
\begin{aligned}
& \delta_{m}(c, m) / \delta_{c}(c, m)=0 \\
& \delta(c, m)=f^{\prime}(K(c))-n
\end{aligned}
$$

Solving these simultaneously gives the optimal quantities of consumption and real balances. In order for such quantities to exist, there must be a point along any indifference curve of $\delta(c, m)$ at which the marginal rate of substitution between $m$ and $c$ is reduced to zero - here the term 'the marginal rate of substitution' is used for the function $\delta(c, m)$. Once these optimum quantities of $c$ and $m$ are determined, we may turn to the condition that the marginal rate of substitution between the two equals the nominal interest rate, which, in turn, equals the inflation plus the net real interest rate; that is, in steady state, it holds that:

$$
\delta_{m}(c, m) / \delta_{c}(c, m)=i(t)=0=\pi+f^{\prime}\left(k^{*}\right)-n
$$

Because the growth rate of money supply, $\theta$, equals the inflation rate minus the fertility rate, $n$ (i.e., $\theta=\pi-n$ ), $\theta$ must equal the negative of the real interest rate, $-f^{\prime}\left(k^{*}\right)$, for condition (63) to hold. That is,

$$
\theta=-f^{\prime}\left(k^{*}\right)
$$

This confirms Friedman's rule that money be contracted at the rate of the real interest rate so that the nominal interest rate (the holding cost of real balances) is reduced to zero, thereby causing the agent to hold enough real balances to bring the marginal rate of substitution down to zero. Figure 3 illustrates how the optimum quantity is determined at point $E$.

With money in the utility function, it can be shown that money is non-superneutral in the sense that, as of steady state, an increase in the growth rate of money supply 


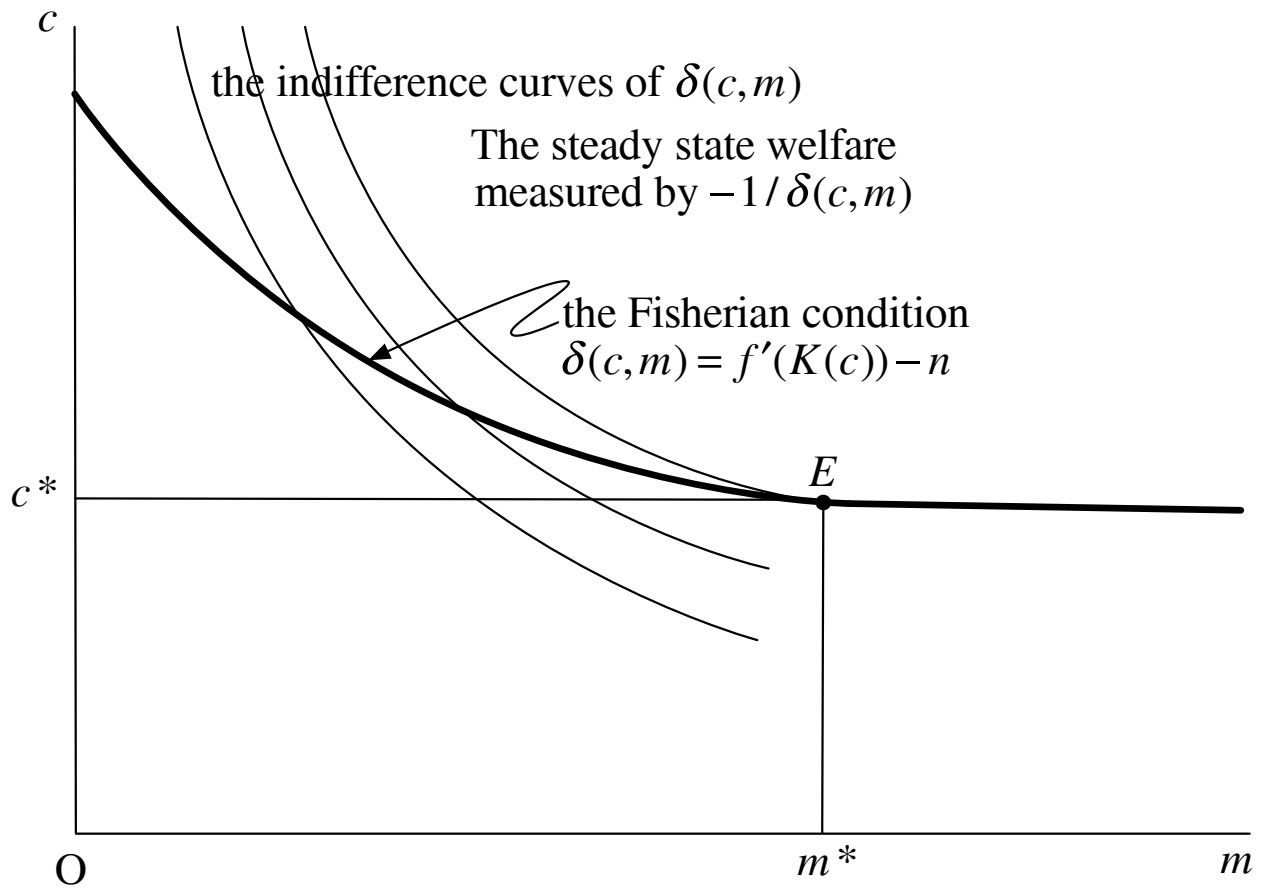

Figure 3. Determination of the optimum quantity of money

Note: At point E, the marginal rate of substitution between real balances and consumption equals zero.

raises the nominal interest rate; hence real balance holdings fall, which lowers the rate of time preference, thereby raising the steady state capital intensity and consumption. But, an induced increase in consumption is not enough to compensate a fall in real balance holdings, hence steady state welfare declines. This can be seen by examining the two conditions: one is the Fisherian condition which states the rate of time preference equals the net marginal product of capital, and the other is the condition requiring that the marginal rate of substitution between real balances and consumption be equal to the nominal interest rate. In steady state, they are given as:

$$
\begin{aligned}
& \delta(c, m)=f^{\prime}(K(c))-(d+n) \\
& \delta_{m}(c, m) / \delta_{c}(c, m)=i(t)=\pi+f^{\prime}(K(c))-n
\end{aligned}
$$

These conditions are drawn in Figure 4. The Fisherian condition is drawn as a downward-sloping curve which eventually flattens, and the second is the marginal rate of substitution (MRS) condition requiring that this rate be equal to the nominal interest rate, which is positively sloped. As $\theta$ is increased, the MRS-schedule shifts upward, thereby reducing $m$ but increasing $c$ along the Fisherian condition, as seen by a shift from point $A$ to point $B$ in Figure 4 . A decrease in $m$, on the other hand, reduces the rate of time preference, hence increases capital intensity, which was shown by a shift 


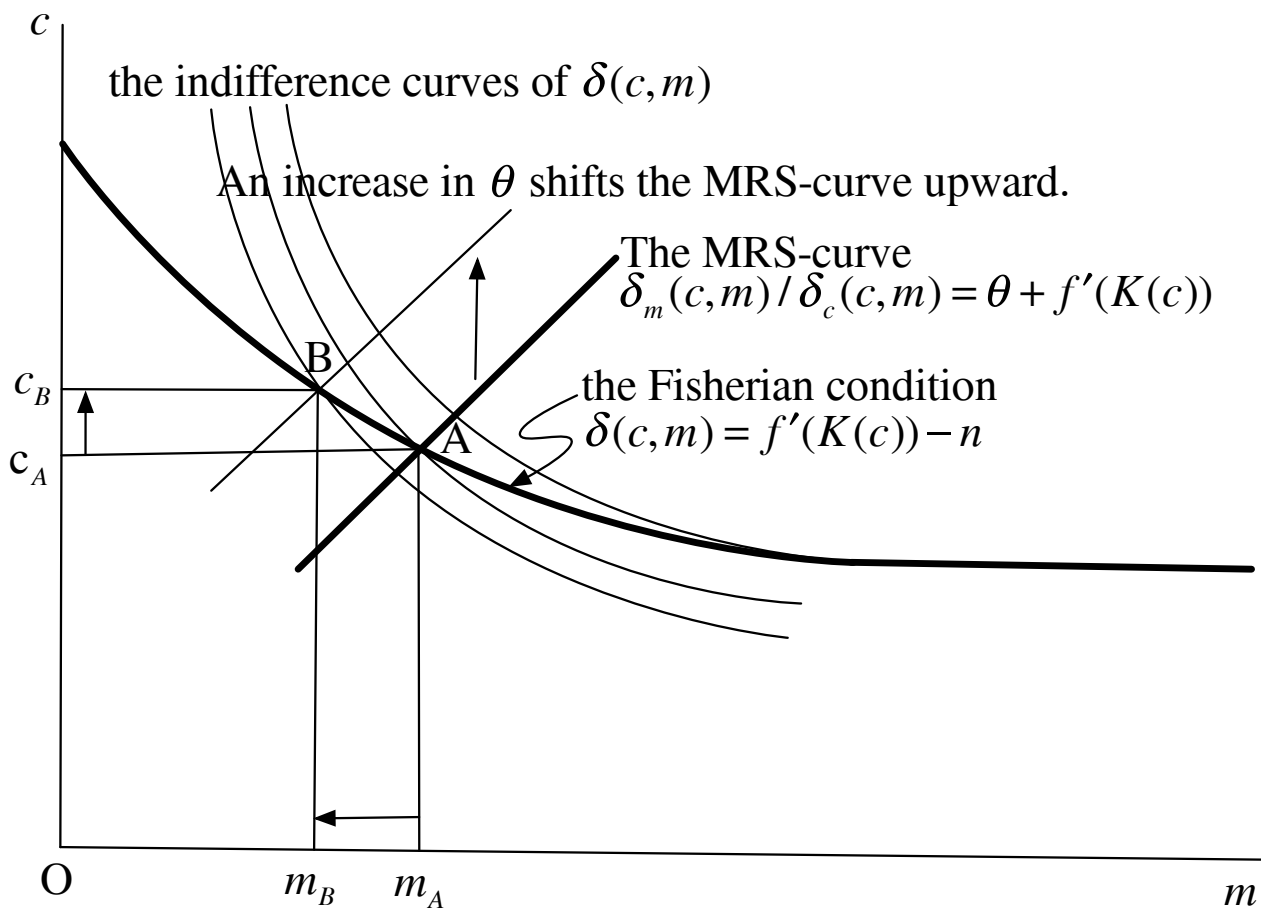

Figure 4. Money growth rate, consumption and real balances Note: An increase in the money growth rate $\theta$ affects the steady-state consumption and real balances, resulting in a fall in the agent's welfare.

from point $A$ to point $B$ in Figure 2. Since the rate of time preference is complementary to the steady state welfare indicated by $-1 / \delta(c, m)$, the welfare declines. Thus, money is non-superneutral since while capital intensity (and consumption) is affected positively by the rate of monetary expansion, welfare declines because an increase in consumption is not enough to compensate a fall in real balance holdings; in Figure 4, point $B$ lies on a lower indifference curve than point $A$. Friedman's rule assures that if money is contracted at the rate of the real interest rate, $\delta(c, m)$ is maximised, which also maximises the steady-state welfare as shown in Figure 3.

Thus, whether Friedman's idea of the optimum quantity of money and the related optimum rule of money supply applies or not hinges on whether it is imputed transaction services of real balances or the stock itself of such balances that is considered in the utility function. In the case of the former, all of capital intensity, consumption, transaction services, the rate of time preference, and welfare remain unaffected by money. Money is, therefore, completely neutral to steady state, and Friedman's idea no longer applies. On the other hand, in the case of the money in the utility function, money affects all of these quantities. Also, in the latter case, steady state transaction services measured by foregone nominal interest earnings (im) will increase in response 
to a higher growth rate of money supply since the condition $d m / d \theta>-m / i$ will hold (i.e., the real balance holdings will not fall as much as $m / i$ ). That is,

$$
\frac{d}{d \theta}(i m)=\frac{d i}{d \theta} m+i \frac{d m}{d \theta}=m+i \frac{d m}{d \theta}>0
$$

\section{Diminishing Marginal Impatience}

Our analysis in sections 4 and 5 was based on the increasing marginal impatience. If we assume, in line with Becker and Mulligan (1997), that the marginal impatience is diminishing in consumption and real balances, we get opposite results. In reference to Figure 2, in response to an increase in the growth rate of money supply, the quantity of real balances will fall, which now shifts the rate-of-time-preference schedule upward rather than downward, which results in reduced capital intensity. A lower capital intensity is accompanied by reduced consumption. Hence, in steady state, both consumption and real balances are lowered, which raises the welfare as measured by $-1 / \delta(c, m)$. This implies that no contraction of money supply can achieve the optimum quantity of money as argued by Friedman (1969). Thus, we have two opposite results on the issue of the superneutrality of money, depending on whether the marginal impatience is increasing or decreasing in consumption and real balances.

Our treatment of implicit transaction services of money delivers the complete neutrality of money regardless of the nature of the marginal impatience. In fact, as we demonstrated, the transition path also is not affected by the changing nominal interest rates. We believe that this complete neutrality, in steady state as well as along the transition path, and its independence from the property of the marginal impatience are an indication that the general equilibrium could be invariant to the presence of money.

\section{Conclusion}

We have demonstrated that how money affects real decisions of agents depends on how money is represented in their preferences. We put forth an argument that if money is held for its transaction services, a viable alternative to money in the utility function is to enter the imputed transaction services directly in this function. This alternative specification accords well with Walras's distinction between money as a stock and its services of availability as a flow. With imputed transaction services, money turns hyperneutral in that all endogenous variables: capital, consumption, transaction services, the rate of time preference and welfare remain invariant to the monetary expansion in steady state, regardless of the nature of the marginal impatience. This renders Friedman's notion of the optimum quantity of money as well as of the optimum money supply rule inapplicable.

\section{References}

Abel, A.B. (1985). Dynamic behavior of capital accumulation in a cash-in-advance model. Journal of Monetary Economics, 16(1), 55-71. https://doi.org/10.1016/0304-3932(85)90006-6 
Asako, K. (1983). The utility function and the superneutrality of money on the transition path. Econometrica, 51(5), 1593-1596. https:/doi.org/10.2307/1912293

Ascari, G. (1998). Superneutrality of money in staggered wage-setting models. Macroeconomic Dynamics, 2(3), 383-400. https://doi.org/10.1017/\$1365100598008050

Barro, R.J., \& Sala-i-Martin, X. (1995). Economic growth. New York, NY: McGraw-Hill.

Baumol, W.J. (1952). The transactions demand for cash: An inventory theoretic approach. Quarterly Journal of Economics, 66(4), 545-556. https://doi.org/10.2307/1882104

Becker, G.S., \& Mulligan, C.B. (1997). The endogenous determination of time preference. Quarterly Journal of Economics, 112(3), 729-758. https://doi.org/10.1162/003355397555334

Bridel, P. (2002). Patinkin, Walras and the 'money-in-the-utility-function' tradition. European Journal of the History of Economic Thought, 9(2), 268-292. https://doi.org/10.1080/096725 60210130710

Buyer, R.S., \& Hodrick, R.J. (1982). The dynamic adjustment path for perfectly foreseen changes in monetary policy. Journal of Monetary Economics, 9(2), 185-201. https://doi.org/10.1016/ 0304-3932(82)90041-1

Chen, B-L., Hsu, M., \& Lu, C-H. (2008). Inflation and growth: Impatience and a qualitative equivalence. Journal of Money, Credit and Banking, 4O(6), 1309-1323. https://doi.org/10.1111/ j.1538-4616.2008.00159.x

Chen, B.L., Hsu, Y.S., \& Lu, C-H. (2011). Friedman meets Becker and Mulligan in a monetary neoclassical growth model. Journal of Economics, 104(2), 99-126. https://doi.org/10.1007/ s00712-011-0224-x

Clower, R.W. (1967). A reconsideration of the microfoundations of monetary theory. Economic Inquiry, 6(1), 1-8. https://doi.org/10.1111/j.1465-7295.1967.tb01171.x

Clower, R.W., \& Riley, J.G. (1976). The foundations of money illusion in a neoclassical micromonetary model: Comment. American Economic Review, 66(1), 184-185.

Cohen, D. (1985). Inflation, wealth and interest rates in an intertemporal optimizing model. Journal of Monetary Economics, 16(1), 73-85. https://doi.org/10.1016/0304-3932(85)90007-8

Deev, O., \& Hodula, M. (2016). The long-run superneutrality of money revised: The extended European evidence. Review of Economic Perspectives, 16(3), 187-203. https://doi.org/ 10.1515/revecp-2016-0012

Dusansky, R., \& Kalman, P.J. (1974). The foundations of money illusion in a neoclassical micromonetary model. American Economic Review, 64(1), 115-122.

Dusansky, R., \& Kalman, P.J. (1976). The foundations of money illusion in a neoclassical micromonetary model: Reply. American Economic Review, 66(1), 192-195.

Epstein, L.G. (1987a). A simple dynamic general equilibrium model. Journal of Economic Theory, 41(1), 68-95. https://doi.org/10.1016/0022-0531(87)90006-8

Epstein, L.G. (1987b). The global stability of efficient intertemporal allocations. Econometrica, 55(2), 329-355. https://doi.org/10.2307/1913239

Epstein, L.G., \& Hynes, J.A. (1983). The rate of time preference and dynamic economic analysis. Journal of Political Economy, 91(4), 611-635. https://doi.org/10.1086/261168

Feenstra, R.C. (1986). Functional equivalence between liquidity costs and the utility of money, Journal of Monetary Economics, 17(2), 271-291. https://doi.org/10.1016/0304-3932(86) 90032-2

Fischer, S. (1979). Capital accumulation on the transition path in a monetary optimizing model. Econometrica, 47(6), 1433-1439. https://doi.org/10.2307/1914010

Friedman, M. (1969). The optimum quantity of money. In M. Friedman (Ed.), The optimum quantity of money and other essays (pp. 1-50). Chicago, IL: Aldine.

Gale, D. (2010). Money and general equilibrium. In S.N. Durlauf \& L.E. Blume (Eds.), Monetary economics (pp. 242-249). The New Palgrave Economics Collection. London: Palgrave Macmillan. https://doi.org/10.1057/9780230280854_28 
Gong, L. (2006). Endogenous time preference, inflation, and capital accumulation. Journal of Economics, 87(3), 241-255. https://doi.org/10.1007/s00712-006-0177-7

Groth, C. (2017). Lecture notes in macroeconomics (mimeo). Retrieved from http://web.econ. ku.dk/okocg/VM/VM-general/Material/Chapters-VM.htm

Hayakawa, H. (1984). A dynamic generalization of the Tobin model. Journal of Economic Dynamics and Control, 7(3), 209-231. https://doi.org/10.1016/0165-1889(84)90017-4

Hayakawa, H. (1986). Intertemporal optimization and neutrality of money in growth models. Journal of Monetary Economics, 18(3), 323-328. https://doi.org/10.1016/0304-3932(86)90044-9

Hayakawa, H. (1991). On the rate of time preference under recursive preferences. Economics Letters, 36(4), 347-354. https://doi.org/10.1016/0165-1765(91)90196-R

Hayakawa, H. (1992). The nonneutrality of money and the optimal monetary growth when preferences are recursive: Cash-in-advance vs. money in the utility function. Journal of Macroeconomics, 14(2), 233-266. https://doi.org/10.1016/0164-0704(92)90043-8

Hayakawa, H. (1994). Time cost of transactions and the superneutrality of money: A reformulation of the Stockman-Abel cash-in-advance model. Economic Studies Quarterly, 45(1), 14-31. https://doi.org/10.11398/economics1986.45.14

Hayakawa, H., \& Ishizawa, S. (1993). The fundamental principle of intertemporal optimization: Consumer behavior under recursive preferences. Economics Letters, 41(3), 273-280. https:// doi.org/10.1016/0165-1765(93)90153-4

Hayakawa, H., \& Ishizawa, S. (1997). The fundamentals of intertemporal optimization in the continuous time modeling of consumer behavior. Japanese Economic Review, 48(1), 101-112. https://doi.org/10.1111/1468-5876.00039

Hicks, J.R. (1935). A suggestion for simplifying the theory of money. Economica, 2(5), 1-19. https://doi.org/10.2307/2549103

Homburg, S. (2015). Superneutrality of money under open market operations. Review of Economics, 66(3), 289-302. https://doi.org/10.1515/roe-2015-1003

Johnson, H.G. (1966). The neo-classical one-sector growth model: A geometrical exposition and extension to a monetary economy. Economica, 33(131), 265-287. https://doi.org/10.2307/ 2552404

Koopmans, T.C. (1960). Stationary ordinary utility and impatience. Econometrica, 28(2), 287-309. https://doi.org/10.2307/1907722

Koopmans, T.C. (1986). Representation of preference ordering over time. In C.B. McGuire \& R. Radner (Eds.), Decision and organization (2nd ed., pp. 79-100). Minneapolis, MN: University of Minnesota Press.

Levhari, D., \& Liviatan, N. (1972). On stability in the saddle-point sense. Journal of Economic Theory, 4(1), 88-93. https://doi.org/10.1016/0022-0531(72)90165-2

Lioui, A., \& Poncet, P. (2008). Monetary non-neutrality in the Sidrauski model under uncertainty. Economics Letters, 100(1), 22-26. https://doi.org/10.1016/j.econlet.2007.10.023

Longaretti, R., \& Gatti, D.D. (2004). Monetary policy and the distribution of wealth in a OLG economy with heterogeneous agents, money and bequests. In M. Gallegati, A.P. Kirman, \& M. Marsili (Eds.), The complex dynamics of economic interaction (pp. 15-33). Berlin: SpringerVerlag. https://doi.org/10.1007/978-3-642-17045-4_2

Longaretti, R., \& Gatti, D.D. (2006). The non-superneutrality of money and its distributional effects when agents are heterogeneous and capital markets are imperfect (Working Paper No. 95). Milan, Italy: Dipartimento di Economia Politica, Università degli Studi di Milano-Bicocca.

Lucas, R.E. (1972). Expectations and the neutrality of money. Journal of Economic Theory, 4(2), 103-124. https://doi.org/10.1016/0022-0531(72)90142-1

McCallum, B.T. (1983). The role of overlapping-generations models in monetary economics. Carnegie-Rochester Conference Series on Public Policy, 18, 9-44. https://doi.org/10.1016/ 0167-2231(83)90020-9 
Mundell, R. (1963). Inflation and real interest, Journal of Political Economy, 71(3), 280-283. https://doi.org/10.1086/258771

Orphanides, A., \& Solow, R.M. (1990). Money, inflation and growth. In B.M. Friedman \& F.H. Hahn (Eds.), Handbook of monetary economics, Vol. 1 (pp. 223-261). Amsterdam: Elsevier Science Publishers. https://doi.org/10.1016/s1573-4498(05)80009-8.

Ostroy, J.M. (1989). Money and general equilibrium theory. In J. Eatwell, M. Milgate \& P. Newman (Eds.), General equilibrium (pp. 187-193). London: Palgrave Macmillan. https://doi.org/ 10.1007/978-1-349-19802-3_22

Patinkin, D. (1956). Money, interest and prices. Evanston, IL: Row Peterson.

Patinkin, D. (1987). Neutrality of money. In J. Eatwell, M. Milgate \& P. Newman (Eds.), The new Palgrave dictionary of economics (pp. 639-645). London: Macmillan Press. https://doi. org/10.1057/978-1-349-95121-5_957-1

Rapach, D.E. (2003). International evidence on the long-run impact of inflation. Journal of Money, Credit and Banking, 35(1), 23-48.

Reis, R. (2007). The analytics of monetary non-neutrality in the Sidrauski model. Economics Letters, 94(1), 129-135. https://doi.org/10.1016/j.econlet.2006.08.017

Samuelson, P.A. (1958). An exact consumption-loan model of interest with or without the social contrivance of money. Journal of Political Economy, 66(6), 467-482.

Sidrauski, M. (1967a). Rational choice and patterns of growth in a monetary economy. Journal of Political Economy, 77( 4), Part 2 (Jul. - Aug., 1969): 575-585. https://doi.org/10.1086/259552

Sidrauski, M. (1967b). Inflation and economic growth. Journal of Political Economy, 75(6), 796810. https://doi.org/10.1086/259360

Stockman, A.C. (1981). Anticipated inflation and the capital stock in a cash in-advance economy. Journal of Monetary Economics, 8(3), 387-393. https://doi.org/10.1016/0304-3932(81) 90018-0

Tobin, J. (1956). The interest elasticity of the transactions demand for cash. Review of Economics and Statistics, 38(3), 241-247. https://doi.org/10.2307/1925776

Tobin, J. (1965). Money and economic growth. Econometrica, 33(4), 671-684. https://doi.org/ $10.2307 / 1910352$

Uzawa, H. (1968). Time preference, the consumption function, and optimum asset holdings. In J.N. Wolfe (Ed.), Value, capital and growth: Papers in honour of Sir John Hicks (pp. 485-505). Edinburgh: University of Edinburgh Press.

Vaona, A. (2016). Anomalous empirical evidence on money long-run super-neutrality and the vertical long-run Phillips curve (Working Paper no. 2038). Kiel, Germany: Kiel Institute for World Economy. Retrieved from https://econpapers.repec.org/paper/zbwifwkwp/2038.htm

Volterra, V. (1959). Theory of functionals and integral and integro-differential equations. Mineola, New York: Dover Publications Inc.

Walras, L. (1874). Elements of pure economics. English translation by W. Jaffe (1954). London: Allen and Unwin.

Wan, H.Y., Jr. (1970). Optimal saving programs under intertemporally dependent preferences. International Economic Review, 11(3), 521-547. https://doi.org/10.2307/2525330

Wang, G. (2012). Keynesian time preferences and monetary superneutrality (MPRA Paper No. 39396). Munich, Germany: Munich University Library. Retrieved from https://mpra.ub.unimuenchen.de/39396/

Wang, P., \& Yip, C.K. (1992a). Examining the long-run effect of money on economic growth. Journal of Macroeconomics, 14(2), 359-369. https://doi.org/10.1016/0164-0704(92)90050-I

Wang, P., \& Yip, C.K. (1992b). Alternative approaches to money and growth. Journal of Money, Credit and Banking, 24(4), 553-562. https://doi.org/10.2307/1992811

Wichers, C.R. (1976). The foundations of money illusion in a neoclassical micro-monetary model: Comment. American Economic Review, 66(1), 186-191. 
